\title{
COMMENTARY
}

\section{The earthquake and tsunami - observations by Japanese physicians since the 11 March catastrophe}

\author{
Soichiro Nagamatsu'*, Tsuyoshi Maekawa², Yoshihito Ujike³, Satoru Hashimoto ${ }^{4}$ and Nobuo Fuke ${ }^{5}$; \\ The Japanese Society of Intensive Care Medicine
}

\begin{abstract}
Japan was struck by a magnitude 9.0 earthquake and a tsunami on 11 March 2011. Although this catastrophe has caused the most devastating damage to Japan since World War II, we believe that our systematic preparation for disasters somewhat alleviated the damage. Learning lessons from the magnitude 7.3 Great Hanshin earthquake in 1995, the government organized approximately 700 medical teams specialized in disaster management. In this earthquake of 2011, hundreds of medical teams were successfully deployed and started operations within the first 72 hours. Furthermore, the internet, which was not commonly used in 1995, made significant contributions in communication among clinicians and enabled them to promptly identify the needs of the affected hospitals. In addition, medical professional societies took leadership in the logistics of transferring victims away from the disaster zone. We also observed that the spectrum of causes of death is distinct between the earthquakes of 1995 and 2011. In 1995, many victims died from trauma, including crash injury, and delays in providing hemodialysis contributed to additional deaths. In 2011, in contrast, many victims died from drowning in the tsunami, and most survivors did not have life-threatening injuries.
\end{abstract}

\section{Introduction}

On 11 March 2011, Japan was struck by a magnitude 9.0 earthquake, the fourth largest earthquake in the world

*Correspondence: nagamatsu-tky@umin.ac.jp

'Division of Pulmonary Allergy, Critical Care and Sleep Medicine, Department of Medicine, University of Minnesota, 420 Delaware Street, South East, MMC 276, Minneapolis, MN 55455, USA

Full list of author information is available at the end of the article since 1900 (the Great East Japan earthquake). The earthquake was immediately followed by a tsunami, which at its highest was estimated to be 37.9 meters. In addition, accidents at the Fukushima Daiichi Nuclear Power Plant caused radiation injuries to power plant workers. The number of those killed or missing is reported to be greater than 23,000, and is expected to increase. In this commentary, we report four key observations, focusing on the differences from the Great Hanshin earthquake of 1995, another major devastating earthquake to strike Japan.

\section{Disaster preparations in Japan}

In 1995, Kobe City was struck by a magnitude 7.3 earthquake (the Great Hanshin earthquake). Approximately 6,425 people were killed and 43,772 were injured. Many victims were trapped under collapsed buildings and suffered from crush injuries [1]. The inability to provide hemodialysis for the unpredictably high number of victims contributed to additional deaths. The Ministry of Health, Labor and Welfare reported that 500 deaths could have been prevented if regular healthcare services, as delivered under normal circumstances, had been promptly provided.

In an effort to learn from this experience, in 2005, the Ministry of Health, Labor and Welfare organized medical teams specializing in disaster medicine, called Disaster Medical Assistance Teams (DMATs) [2]. These teams are deployed during the acute phase of a disaster, particularly within the first 48 hours, not only for natural disasters, but also for disasters such as airplane or train crashes. As of 2010, a total of 703 such teams comprising more than 4,300 medical professionals have been registered. Prefectural governors can activate DMATs depending on the magnitude of the disaster. For example, all DMATs from the entire nation would be activated if a large earthquake were to strike the Tokyo metropolitan area.

Immediately after the earthquake of 11 March 2011, DMATs throughout the nation were activated. Within the first 24 hours, more than 300 teams had initiated 


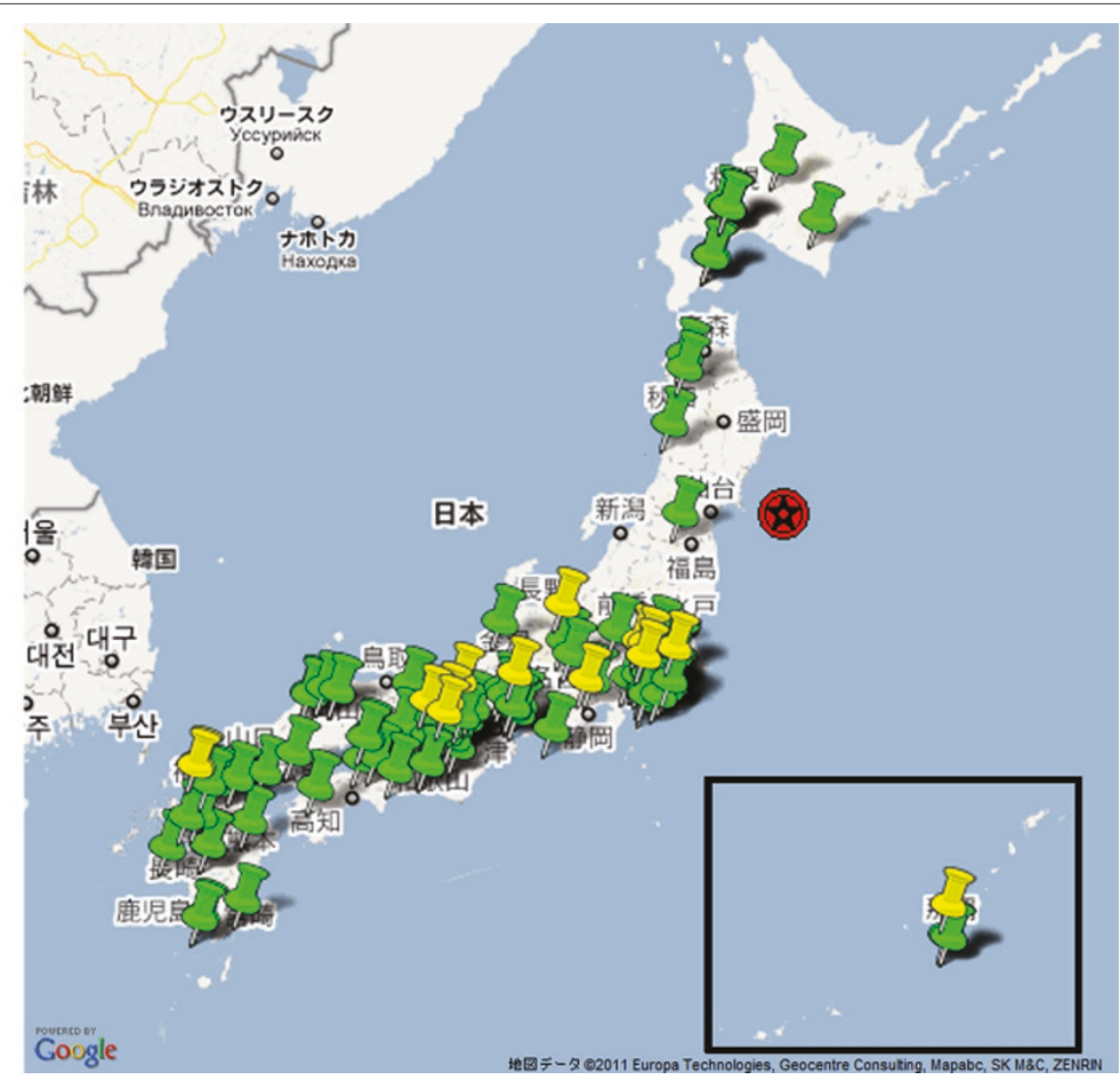

Figure 1. Hospitals with ICU availability are represented by green (adult) and by yellow (pediatrics) pins, using Google Map technology. The red star indicates the epicenter of the magnitude 9.0 earthquake. (Accessed 15 May 2011 at [4].)

medical operations at disaster base hospitals in the Tohoku area, northeastern Japan. In addition to the DMATs, the Japanese Medical Association, the Japanese Red Cross, and many other organizations voluntarily sent medical teams to affected areas.

\section{The spectrum of injuries and drowning death}

The predominance of death by drowning in the Great East Japan earthquake is a clear distinction from the Great Hanshin earthquake, in which hundreds of victims were killed by trauma. The National Police Agency reported that $92.5 \%$ of fatalities were caused by drowning while hospitals were crowded with hundreds of survivors suffering from mild to moderate injuries. According to a DMAT operating at Ishinomaki Red Cross Hospital (402 beds), 4,891 patients presented at the hospital in the first 11 days. The distribution of patients according to triage color was $63.1 \%$ (green, ambulatory), 27.1\% (yellow, serious injury), $7.7 \%$ (red, life-threatening conditions) and $2.0 \%$ (black, death). The most common conditions were pneumonia from aspiration of seawater or cellulitis from wounds, and such victims were not critically ill enough to require ICU admission. Dozens of patients with red tags were transferred by helicopter to Sendai, the nearest metropolitan area.

Learning from lessons of the Great Hanshin earthquake, several DMATs were assigned to airports in anticipation of transporting patients who required urgent hemodialysis to non-affected areas; however, most of these DMATs were not required because of the absence of major trauma patients.

\section{Use of internet technology}

In the 2011 earthquake, advances in internet technology enabled clinicians to promptly identify the needs of the affected area, which made a noticeable difference to disaster response compared with the Great Hanshin earthquake of 1995. Cell-phone signal and internet access were regained by the next day in some areas and by three days in most areas. Using email lists or social network services, such as Twitter, affected hospitals and individual physicians provided timely reports of their medical resource status - for example, that 'water, food, medication, and dialysate will run out by tomorrow'.

These mutual communications on the internet enabled professional societies to promptly assess what resources 
were needed as well as provide information on which facilities patients were to be transferred to. For instance, the Japanese Society of Intensive Care Medicine (JSICM) opened a dialogue via a newly established email list to discuss the medical needs. They anticipated that patient transfers would be required on a large scale given the magnitude of the disaster. Information on ICU bed availability, hemodialysis capacity, and reserved mechanical ventilators were collected and became open to the public within the first 48 hours of the earthquake on their website using Google Map technology (Figure 1).

\section{Disrupted primary care and the vulnerable population}

Similar to the Great Hanshin earthquake, the disaster of 2011 endangered vulnerable elderly people because of the disruption to pre-existing primary care, which led to a change in the spectrum of disease after the first 72 hours [3]. At least 282 people died from deteriorating pre-existing chronic medical conditions in the first 2 weeks, even though they were able to be evacuated from the tsunami.

Many victims were barely able to evacuate from the tsunami, and neither could they bring their belongings. People visited hospitals requesting medication for chronic conditions, some of which were scarce, such as immunosuppressive therapies. In addition, hospitals were isolated from their regular supply networks. Therefore, these vulnerable people had to wait for a weeks knowing that their chronic medical conditions would deteriorate.

The shortage of dialysate, water, and electricity created a dangerous situation for hemodialysis-dependent patients. Some dialysate manufacturers in Ibaraki Prefecture, on the Pacific coast, immediately announced total non-operational status. Patients with hemodialysis needs voluntarily left the stricken area and reestablished a care routine at new locations, anticipating a long evacuation life.

\section{Conclusion}

We report here observations by Japanese physicians from the first month after the 2011 earthquake. Although this catastrophe has caused the most devastating damage to Japan since World War II, we believe that our systematic preparation for disasters somewhat alleviated the damage. Japan is recovering and shall recover fully from this tragedy.

\section{Abbreviations}

DMAT, Disaster Medical Assistance Team; JSICM, Japanese Society of Intensive Care Medicine.

Competing interests

The authors declare that they have no competing interests.

\section{Acknowledgements}

On behalf of the JSICM, we sincerely thank all people and organizations for their sympathy and support regarding the 11 March 2011 tragedy in Japan. We are grateful to the Canadian Critical Care Society, the European Society of Intensive Care Medicine, the Korean Society of Critical Care Medicine, the Society of Critical Care Medicine, and the World Federation of Societies of Intensive and Critical Care Medicine for their compassion and generous offers of assistance to provide critical care services. Additional contributions: we thank the JSICM, its members and Naoyuki Matsuda, MD, PhD, Department of Emergency and Critical Care Medicine, Nagoya University Graduate School of Medicine for providing timely information from the stricken area, and Hiroshi Nonogi MD, PhD, Department of Cardiovascular Medicine, National Cerebral and Cardiovascular Center, and Tetsuya Matoba, MD, PhD, Department of Cardiovascular Medicine, Kyushu University Graduate School of Medical Sciences of the Emergency Cardiovascular Care Committee, the Japanese Circulation Society for creating the hospital map in collaboration with JSICM.

\section{Author details}

'Division of Pulmonary Allergy, Critical Care and Sleep Medicine, Department of Medicine, University of Minnesota, 420 Delaware Street, South East, MMC 276, Minneapolis, MN 55455, USA. ${ }^{2}$ Japanese Society of Intensive Care Medicine, Hive Hongo 3F 3-32-6 Hongo, Bunkyou-ku, Tokyo, 113-0033, Japan. ${ }^{3}$ Emergency and Critical Care Medicine, Okayama University, 2-5-1 Shikata-cho, Kita-ku, Okayama-shi, Okayama, 700-8558, Japan. ${ }^{4}$ Department of Anesthesiology and Intensive Care, Kyoto Prefectural University of Medicine, Kawaramachi Hirokoji, Kamigyo, Kyoto, 602-8566, Japan. ${ }^{5}$ Emergency and Intensive Care Center, Teikyo University Chiba Medical Center, 3426-3 Anesaki, Ichihara-shi, Chiba, 299-0001, Japan.

Published: 28 June 2011

\section{References}

1. Kuwagata Y, Oda J, Tanaka H, Iwai A, Matsuoka T, Takaoka M, Kishi M, Morimoto F, Ishikawa K, Mizushima Y, Nakata Y, Yamamura H, Hiraide A, Shimazu T, Yoshioka T: Analysis of 2,702 traumatized patients in the 1995 Hanshin-Awaji earthquake. J Trauma 1997, 43:427-432.

2. Fuse A, Yokota H: An analysis of Japan Disaster Medical Assistance Team (J-DMAT) deployments in comparison with those of J-DMAT's counterpart in the United States (US-DMAT). J Nippon Med Sch 2010, 77:318-324.

3. Tanida $\mathrm{N}$ : What happened to elderly people in the great Hanshin earthquake. BMJ 1996, 313:1133-1135.

4. Japanese Society of Intensive Care Medicine [http://www.jsicm.org/map/]

doi:10.1186/cc10261

Cite this article as: Nagamatsu S, et al.: The earthquake and tsunami observations by Japanese physicians since the 11 March catastrophe. Critical Care 2011, 15:167. 